\title{
The impact of ice layers on gas transport through firn at the North Greenland Eemian Ice Drilling (NEEM) site, Greenland
}

\author{
K. Keegan, M. R. Albert, and I. Baker \\ Thayer School of Engineering, Dartmouth College, Hanover, NH, USA \\ Correspondence to: K. Keegan (kaitlin.m.keegan.th@dartmouth.edu)
}

Received: 13 January 2014 - Published in The Cryosphere Discuss.: 10 February 2014

Revised: 22 July 2014 - Accepted: 22 July 2014 - Published: 1 October 2014

\begin{abstract}
Typically, gas transport through firn is modeled in the context of an idealized firn column. However, in natural firn, imperfections are present, which can alter transport dynamics and therefore reduce the accuracy of reconstructed climate records. For example, ice layers have been found in several firn cores collected in the polar regions. Here, we examined the effects of two ice layers found in a NEEM, Greenland firn core on gas transport through the firn. These ice layers were found to have permeability values of 3.0 and $4.0 \times 10^{-10} \mathrm{~m}^{2}$, and are therefore not impermeable layers. However, the shallower ice layer was found to be significantly less permeable than the surrounding firn, and can therefore retard gas transport. Large closed bubbles were found in the deeper ice layer, which will have an altered gas composition than that expected because they were closed near the surface after the water phase was present. The bubbles in this layer represent $12 \%$ of the expected closed porosity of this firn layer after the firn-ice transition depth is reached, and will therefore bias the future ice core gas record. The permeability and thickness of the ice layers at the North Greenland Eemian Ice Drilling (NEEM) site suggest that they do not disrupt the firn-air concentration profiles and that they do not need to be accounted for in gas transport models at NEEM.
\end{abstract}

\section{Introduction}

In the colder regions of an ice sheet, glacial ice is formed from the densification of snow due to the overburden pressure of successive precipitation. This change from snow to ice occurs over hundreds of years in a region at the top of the ice sheet, known as the "firn layer". The firn layer thickness is typically $40-120 \mathrm{~m}$ in depth, depending on the site conditions, and contains interconnected pore space within the layers of firn. The interconnected pore space allows gases from the overlying atmosphere to diffuse to the bottom of the diffusive zone of the firn column, where they are trapped in bubbles as the deepest firn layers become ice. However, firn-air within the firn layer has a distribution of ages due to diffusive mixing (Schwander et al., 1993). Nevertheless, an inherent age difference ( $\Delta$ age) exists between the ice and the bubbles it traps, because of the interconnected pore space in the firn layer (Schwander and Stauffer, 1984). This $\Delta$ age is an important parameter for interpreting ice-core records.

Melt events occasionally occur in the dry snow region of polar ice sheets, including the widespread events observed on the Greenland ice sheet in 1889 (Keegan et al., 2014) and 2012 (Nghiem et al., 2012, Bennartz et al., 2013). The meltwater from these events refreezes into ice layers within the snowpack near the surface of the ice sheet, and disrupts the interconnected pore space in that area. The rate of gas transport through the firn column is modeled assuming steady state diffusion through a continuously connected pore space, which decreases monotonically with depth through the firn column until the lock-in depth (Buizert et al., 2012). Therefore, the models do not account for any pore space disruption due to ice layers formed from melt. At the Law Dome site, a low permeability section of the firn column was needed to reconcile the modeled gas diffusivity profile with discrete firn gas samples due to the presence of an ice layer (Trudinger et al., 1997). However, it is unclear as to when we need to account for ice layers when modeling gas transport through the firn.

In this study, we examine the permeability of ice layers found in a firn core retrieved from the North Greenland 
Eemian Ice Drilling (NEEM) site, Greenland, in an effort to understand the impact that ice layers have on gas transport through the firn column. We also investigate microstructural properties of these ice layers, and discuss the effect of air bubbles included in the layers during the refreezing process. Lastly, we discuss ways to address the problem of ice layers when modeling gas transport through firn.

\section{Methods}

\subsection{NEEM firn core}

The NEEM 2009 S2 shallow-firn core was drilled in July 2009 from a firn-air sampling site approximately $1 \mathrm{~km}$ from the main drilling site at NEEM, Greenland. The core was drilled to a depth of $76 \mathrm{~m}$ and shipped back to the laboratory for analysis. In the cold laboratory, we recorded the stratigraphy and grain size with $1 \mathrm{~mm}$ resolution for the entire length of the core. We then cut the core into subsections of 5-10 cm in height, retaining samples of homogeneous layering as often as possible. The physical dimensions of each core piece were measured using calipers and a millimeterscale rule, and any imperfections in the sample were noted. The mass of each core piece was measured using a calibrated balance. We calculated the density for each core subsection from the measured height, diameter, and mass for each, with an instrumental error $0.05 \mathrm{~g} \mathrm{~cm}^{-3}$.

\subsection{Permeability}

Permeability is a measure of a porous medium's ability to transport fluids through its interconnected pore space. Using Darcy's law (Eq. 1), permeability is defined as the proportionality constant, $k$, which relates the pressure gradient to the fluid flow rate through the sample:

$v=\frac{k}{\mu} \frac{\Delta P}{\Delta z}$,

where $v$ is the Darcy fluid velocity, $\mu$ is the fluid viscosity, $P$ is the pressure, and $z$ is the height of the sample. Therefore, $\Delta P / \Delta z$ is the pressure gradient across the sample, where $\Delta P$ is the pressure drop and $\Delta z$ is the length of the core section.

Diffusivity is described by Fick's second law of diffusion:

$$
\frac{\partial c}{\partial t}=D \frac{\partial^{2} c}{\partial z^{2}}
$$

where $c$ is gas concentration, $t$ is time, $D$ is diffusivity, and $z$ is depth. Freitag et al. (2002) found a power-law relationship between permeability and diffusivity, which was modified by Adolph and Albert after measuring the diffusivity and permeability of firn samples, and found to be:

$k=10^{-6.973} \mathrm{~m}^{2}\left(\frac{D_{\mathrm{f}}}{D_{\mathrm{a}}},\right)^{b}$ where $b$ is a constant that is experimentally determined for each material, $D_{\mathrm{f}}$ is the diffusivity in firn, and $D_{\mathrm{a}}$ is the diffusivity in free air (Freitag et al., 2002; Adolph and Albert, 2013). It was found that the $b$ value for firn at Summit, Greenland, is 1.50 . In deep firn, the permeability is linearly related to the gas diffusivity (Adolph and Albert, 2013).

To determine the permeability of our firn core, we measured the $\Delta P / \Delta z$ pressure drop over the height of each homogenous subsection of firn while varying the flow rate of air through the samples using a custom-developed permeameter (Albert et al., 2000). The measured geometrical dimensions, flow rate, pressure drop, air temperature, and barometric pressure were then used to calculate the permeability from Darcy's law. Measurements that were outside of the linear flow range, and therefore violate Darcy's law, were not used. On average, 8 to 10 permeability measurements were made on each sample using different flow rates.

While there are differences between the lateral and vertical permeability measurements of a core sample, it was found that these directional differences are much smaller than the difference in permeability measurements in the vertical direction of core samples from different layers (Luciano and Albert, 2002). The permeability measurements reported here are in the vertical direction of our firn core.

Replicate permeability measurements on the same firn samples vary by $3 \%$, and similar measurements on standard glass beads vary by $6 \%$. It was also found that the permeability measured for different samples at a given firn depth varied by up to $10 \%$ due to lateral spatial heterogeneity within the recovered cross section of the core (Albert et al., 2000). Therefore, we assume error of up to $10 \%$ for permeability measurements due to the analysis of a single firn core at this site. The lower limit of permeability measurement is $0.1 \times 10^{-10} \mathrm{~m}^{2}$, and any measurement below this value is considered to be impermeable in this paper.

\subsection{X-ray micro-computed tomography}

We examined the three-dimensional structure of the firn and ice layers in the core using X-ray micro-computed tomography (micro-CT). Using a Skyscan 1172 micro-CT scanner housed within in a cold room, we scanned $10 \times 10 \times 15 \mathrm{~mm}$ samples containing the ice layers. We used the software programs NRECON ${ }^{\mathrm{TM}}, \mathrm{CTAn}^{\mathrm{TM}}$, and $\mathrm{CTVol}^{\mathrm{TM}}$ to reconstruct the three-dimensional images and calculate microstructural properties of the ice layer samples. The microstructural properties we examined were closed porosity, number of closed pores, and volume of closed pores.

\section{Results and discussion}

\subsection{NEEM ice layers}

We identified two ice layers in the NEEM firn core at 27.3 and $44.3 \mathrm{~m}$ (Fig. 1). These ice layers are 1-2 cm in thickness, 


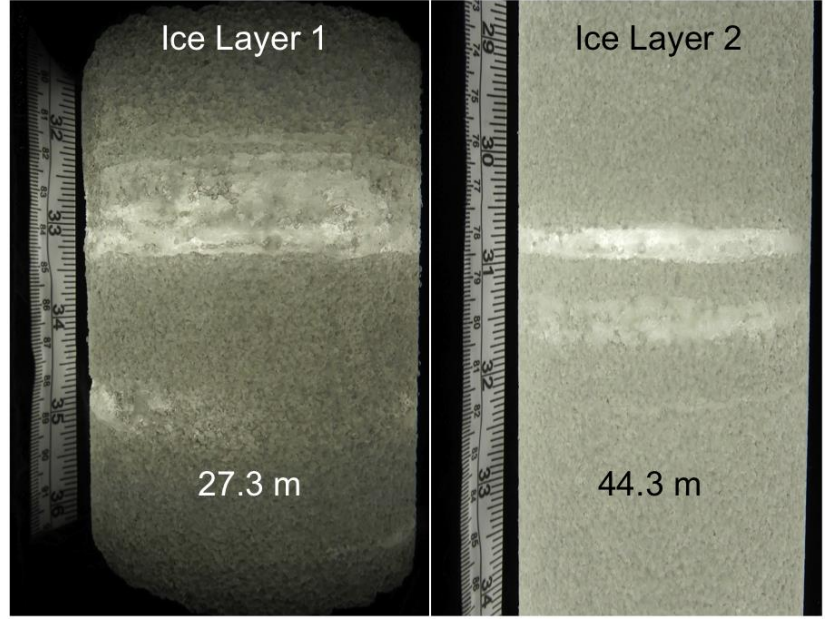

Figure 1. The two ice layers in the 2009 NEEM firn core; (left) ice layer 1 located at $27.3 \mathrm{~m}$ depth, and (right) ice layer 2 located at $44.3 \mathrm{~m}$ depth.

are comprised of ice without grain boundaries, and exhibit multiple ice horizons in close proximity at both depths. The structure of the ice layers is distinctly different from that of wind crusts, which are mono-grain layers of wind-packed snow that are approximately $1 \mathrm{~mm}$ in thickness and are commonly found in firn stratigraphy (Alley, 1988). The thickness of the NEEM ice layers indicates that they were formed from the refreezing of meltwater within the near-surface snowpack at this site. The presence of multiple ice horizons at both ice layer depths is an indication that there was ample melting to cause percolation of meltwater deeper into the firn. The depth of the multiple underlying melt layers at a given site will depend on the nature of the melt event, the permeability of the firn, temperature of the firn, and the amount of liquid water available for percolation.

Using a depth-age scale reconstructed on the basis of seasonal variations in sodium (Na), non-sea-salt sulfur (nssS), black carbon (BC), non-sea-salt calcium (nssCa), and the ratio of nssS/Na (Sigl et al., 2013), the shallower ice layer (ice layer 1) was dated to 1941 and the deeper ice layer (ice layer 2) was dated to 1888 . Interestingly, it was found that ice layer 2 was formed from the last widespread surfacemelting event on the Greenland ice sheet in 1889 (Keegan et al., 2014), which produced ice layers that are clearly visible in firn cores retrieved from many sites across Greenland. Ice layer 1 appears to have been formed from a local melting event at NEEM, as it has not been identified in other Greenland firn cores.

The firn density profiles near each ice layer are shown in Fig. 2. At the depths $23.5-28.5 \mathrm{~m}$ (Fig. 2a), the $95 \%$ prediction interval (gray lines) calculated from the local densification rate (black line) shows that the density of the sample containing ice layer $1\left(0.65 \mathrm{~g} \mathrm{~cm}^{-3}\right)$ is at the upper limit of the expected density. Conversely, Fig. $2 b$ shows that the
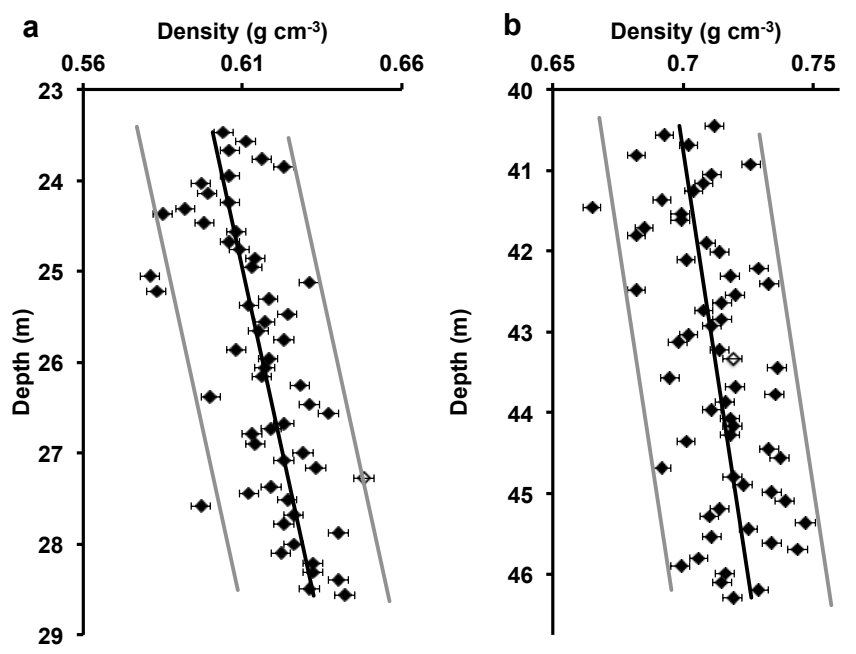

Figure 2. The density profiles near (a) ice layer 1, and (b) ice layer 2, where the closed diamonds indicate normal firn core samples and the open diamonds indicate the core sample containing the ice layer, with error bars indicating measurement error of $0.5 \%$. The black line is the densification rate found from the density measurements, and the gray lines indicate the upper and lower bounds of the $95 \%$ prediction interval, calculated based on the densification rate.

Table 1. Microstructural parameters of ice layer bubbles.

\begin{tabular}{lrrrrr}
\hline Sample & $\begin{array}{r}\text { Layer } \\
\text { thickness } \\
(\mathrm{cm})\end{array}$ & $\begin{array}{r}\text { Avg. } \\
\text { bubble } \\
\text { volume } \\
\left(\mathrm{mm}^{3}\right)\end{array}$ & $\begin{array}{r}\text { Max. } \\
\text { bubble } \\
\text { volume } \\
\left(\mathrm{mm}^{3}\right)\end{array}$ & $\begin{array}{r}\text { Bubble } \\
\text { concentration } \\
(\%)\end{array}$ & $\begin{array}{r}\text { Percent } \\
\text { expected } \\
\text { closed } \\
\text { porosity }\end{array}$ \\
\hline Ice layer 1 & 2.0 & 0.03 & 0.07 & 0.2 & 0.5 \\
Ice layer 2 & 0.6 & 0.20 & 2.62 & 6.0 & 12.0 \\
\hline
\end{tabular}

density of the sample containing ice layer $2\left(0.72 \mathrm{~g} \mathrm{~cm}^{-3}\right)$ is not statistically different, as the density value falls within the $95 \%$ predicted interval of densities at that depth. This is due to the extent of firn densification at this depth.

\subsection{Permeability}

The permeability profile of the firn near each ice layer is shown in Fig. 3. Near ice layer 1 (Fig. 3a) the permeability is slightly increasing with depth. The $95 \%$ predicted interval for this depth indicates that the permeability of the sample containing ice layer 1 is significantly lower than the surrounding firn. Despite having a lower permeability of $3.0 \pm 0.3 \times 10^{-10} \mathrm{~m}^{2}$ compared to the surrounding firn, our results show that ice layer 1 is not impermeable. Near ice layer 2 (Fig. 3b) the permeability is decreasing with depth, and the sample containing the ice layer falls within the $95 \%$ predicted interval with a permeability of $4.0 \pm 0.4 \times 10^{-10} \mathrm{~m}^{2}$, and is therefore not less permeable that the surrounding firn. At these depths, the firn layers are 

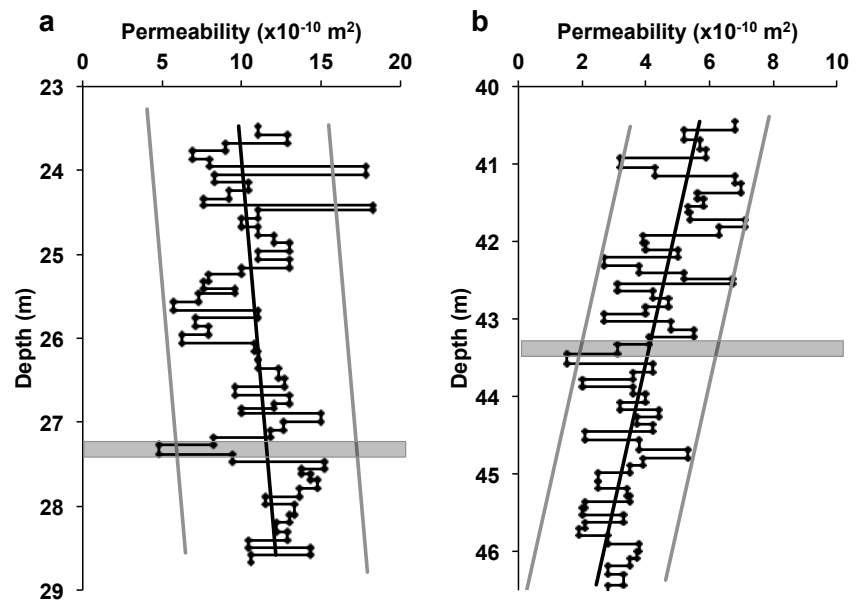

Figure 3. The permeability profiles from the 2009 NEEM firn core, near (a) ice layer 1, (b) ice layer 2, where gray bars indicate ice layer samples. The black line is a linear fit to the permeability measurements, and the gray lines indicate the upper and lower bounds of the $95 \%$ prediction interval, calculated based on the permeability.

more dense and therefore less permeable, causing the permeability of the ice and firn layers to be similar.

\subsection{Microstructure of ice layers}

Reconstructed images of the ice and pore phases of both ice layers are shown in Fig. 4. The ice phase images (Fig. 4a, b) show a continuous ice layer with few pores in both samples, representing the layers seen visually. The pore phase image of ice layer 1 (Fig. 4c) shows one large, horizontally connected pore running through the ice layer, which indicates that there are large pores directing gas transport through the ice layer. The pore phase image of ice layer 2 (Fig. 4d) shows few large, and many small, air bubbles that were trapped in the refreezing process of that layer. The bubbles within the ice layers closed when they were near the surface, and therefore contain atmospheric samples that are much older than bubbles formed normally at the bottom of the firn column.

To investigate the effect that these bubbles have on the NEEM firn-air record, the average bubble size, maximum bubble volume, bubble concentration, and percent of expected closed porosity were calculated from the reconstructed micro-CT images (Table 1). Considering the total volume of pore phase in the micro-CT images, we calculated the bubble concentration to be the fraction of the pore phase found within the closed bubbles. Comparing, the total amount of ice layer 1 contained only small bubbles, and had a bubble concentration of $0.2 \%$. Ice layer 2 contained bubbles with an average volume of $0.75 \mathrm{~mm}^{3}$, with the largest bubble having a closed volume of $2.6 \mathrm{~mm}^{3}$, and a bubble concentration of $6 \%$. Firn that is just past the firn-ice transition depth typically has a density of $0.82 \mathrm{~g} \mathrm{~cm}^{-3}$, and therefore a closed porosity of 0.11 . We normalized the total amount of closed

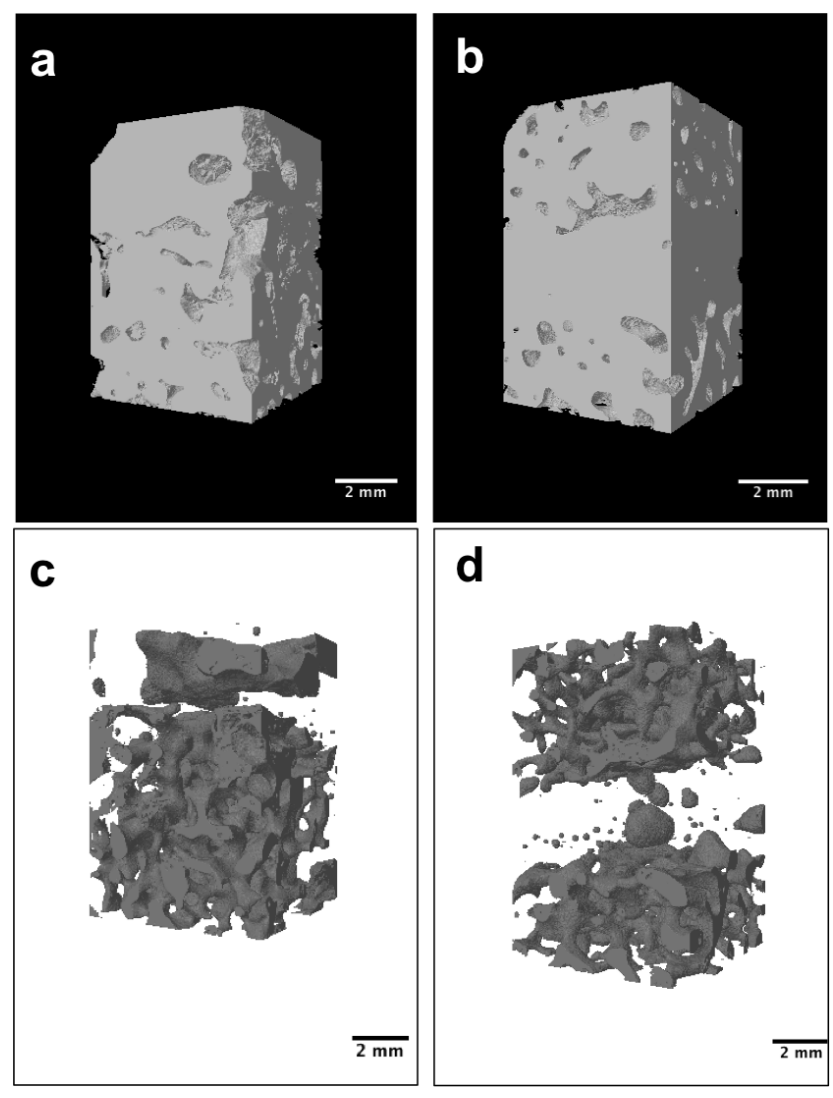

Figure 4. Reconstructed three-dimensional images of sub-samples of the ice phase of (a) ice layer 1 and (b) ice layer 2, and the pore phase of (c) ice layer 1 and (d) ice layer 2.

porosity found in the ice layer bubbles to that of "mature firn" with a closed porosity of 0.11 , and found that the bubbles in ice layer 1 and 2 comprise $0.5 \%$ and $12.0 \%$, respectively, of the expected closed porosity of that firn layer when the firn-ice transition depth is reached.

\subsection{Ice layer effect on gas transport}

Ice layers alter ice core gas records in three distinct ways: affecting gas transport in the open pores (Trudinger et al., 1997), trapping bubbles during the freezing process, and altered air content due to the presence of the water phase (Neftel et al., 1983). The ice layers affect gas transport in the open, interconnected pore space by reducing the permeability, which impedes bulk air movement in response to pressure gradients. Therefore, ice layers in the near surface will decrease convective mixing in the upper firn due to wind pumping. Ice layers will also reduce the gas diffusivity of that layer (Trudinger et al., 1997) and impact the diffusive fluxes of all gases. Consequently, ice layers in the firn layer will reduce the gravitational enrichment of gases within the pore space, and reduce the propagation of transient atmospheric signals into the deeper firn. Despite the NEEM ice layer 1 having a 
lower permeability compared to the surrounding firn, neither NEEM ice layers appear to have had much effect on the open pore gas transport (Buizert et al., 2013). This is likely due to three-dimensional nature of gas transport, and imperfections in the lateral extent of ice layers. The firn-air profile at the DE08-2 site (near Law Dome), Antarctica, demonstrated that ice layers that are located in shallow firn can significantly reduce the diffusivity and gas transport (Trudinger et al., 1997). Further analysis of other sites with ice layers is needed to determine at what thickness, depth in the firn, and lateral extent ice layers will impact gas diffusivity in the firn.

Upon refreezing, air bubbles are trapped into the ice layer. These bubbles closed near the surface, and therefore contain atmospheric samples that are much older than bubbles formed normally at the bottom of the firn column. If bubbles occluded within ice layers are large enough, they will bias the age of gas records to be older than expected at that depth. Despite large bubbles closing off near the surface, ice layers are also noticed for a lack of air content, as the closed porosity is not formed the same way as normal firn layers.

The presence of liquid water during the refreezing process affects the composition of the trapped air bubbles through gas dissolution (Neftel et al., 1983) and possibly biological activity (NEEM Community Members, 2013). Neftel and others found that the water phase allows $\mathrm{CO}_{2}$ to dissolve, which is expelled into the trapped air bubbles during the refreezing process and therefore produces larger-than-expected $\mathrm{CO}_{2}$ concentrations. It has also been found that $\mathrm{CH}_{4}$ and $\mathrm{N}_{2} \mathrm{O}$ are elevated in ice layers from the Dye 3 site in Greenland, along with lowered air content (NEEM Community Members, 2013). Consequently, the composition of the air inside the bubble will not exactly match the atmospheric gas concentrations, and will also differ from that of air bubbles that will form in the surrounding firn once the pore close-off depth is reached. Nevertheless, the air trapped inside the refrozen ice layers will have a biased air composition that is older than expected.

Our study suggests that the ice layers found at the NEEM site are in fact not thick enough to cause a disruption in the firn-air profile. However, the lowered air content of the ice layers, combined with the closed air bubbles found in the refrozen layers, will cause a disruption in the gas record once this firn layer passes the firn-ice transition depth. The DE08-2 study shows that "significant" ice layers, the thickness of which are not published, shallow in the firn column, do affect the diffusivity of the firn, though. Therefore, melting events larger than those seen at NEEM between 1750 and 2009 would be needed to affect the firn-air profile.

\section{Conclusions}

Both ice layers in the NEEM 2009 firn core were permeable, and only the shallower layer was significantly less permeable than the surrounding firn. In both the deep and shal- low ice layers, air bubbles were trapped during the refreezing process of the surface melt. These air bubbles contain atmospheric samples that are much older and probably contain higher concentrations of $\mathrm{CO}_{2}, \mathrm{CH}_{4}$, and $\mathrm{N}_{2} \mathrm{O}$ than expected for the surrounding firn, since they were trapped near the surface while the water phase was present. The microstructure of the ice layers derived from the micro-CT shows that the bubbles in the deeper ice layer will comprise approximately $12 \%$ of the closed porosity when the firn reaches the firn-ice transition depth, and will bias the future ice core gas record at that depth. Taken as a whole, our results suggest that the effects of ice layers do not need to be accounted for when modeling firn gas transport at NEEM. Since ice layers have been found to affect gas transport in the DE08-2 firn, further work is needed at other sites to determine the necessary conditions for ice layers to affect gas transport in polar firn.

Acknowledgements. We thank Z. Courville and the NEEM 2009 firn-air campaign team for assistance in collecting the NEEM 2009-S2 core. Collection and analysis of the core was supported by NSF-ARC 0806339. This work also was supported by NSF-PIRE 0968391 and the Dartmouth College IGERT NSF-DGE 0801490 grants. The authors would also like to acknowledge M. Logan, L. Culler, and M. Battle for their helpful discussions. NEEM is directed and organized by the Center of Ice and Climate at the Niels Bohr Institute and US NSF, Office of Polar Programs. It is supported by funding agencies and institutions in Belgium (FNRS-CFB and FWO), Canada (NRCan/GSC), China (CAS), Denmark (FIST), France (IPEV, CNRS/INSU, CEA and ANR), Germany (AWI), Iceland (RannIs), Japan (NIPR), Korea (KOPRI), The Netherlands (NWO/ALW), Sweden (VR), Switzerland (SNF), United Kingdom (NERC) and the USA (US NSF, Office of Polar Programs).

Edited by: M. Schneebeli

\section{References}

Adolph, A. C. and Albert, M. R.: Gas diffusivity and permeability through the firn column at Summit, Greenland: measurements and comparison to microstructural properties, The Cryosphere, 8, 319-328, doi:10.5194/tc-8-319-2014, 2014.

Albert, M. R. and Perron, F. E.: Ice layer and surface crust permeability in a seasonal snow pack, Hydrol. Process., 14, 3207-3214, 2000.

Albert, M. R., Shultz, E. F., and Perron, F. E.: Snow and firn permeability at Siple Dome, Antarctica, Ann. Glaciol., 31, 353-356, 2000.

Alley, R. B.: Concerning the deposition and diagenesis of strata in polar firn, J. Glaciol., 34, 283-290, 1988.

Bennartz, R., Shupe, M. D., Turner, D. D., Walden, V. P., Steffen, K., Cox, C. J., Kulie, M. S., Miller, N. B., and Pettersen, C.: July 2012 Greenland melt extent enhanced by low-level liquid clouds, Nature, 496, 83-86, 2013.

Buizert, C., Martinerie, P., Petrenko, V. V., Severinghaus, J. P., Trudinger, C. M., Witrant, E., Rosen, J. L., Orsi, A. J., Rubino, M., Etheridge, D. M., Steele, L. P., Hogan, C., Laube, J. C., 
Sturges, W. T., Levchenko, V. A., Smith, A. M., Levin, I., Conway, T. J., Dlugokencky, E. J., Lang, P. M., Kawamura, K., Jenk, T. M., White, J. W. C., Sowers, T., Schwander, J., and Blunier, T.: Gas transport in firn: multiple-tracer characterisation and model intercomparison for NEEM, Northern Greenland, Atmos. Chem. Phys., 12, 4259-4277, doi:10.5194/acp-12-4259-2012, 2012.

Freitag, J., Dobrindt, U., and Kipfstuhl, J.: A new method for predicting transport properties of polar firn with respect to gases on the pore-space scale, Ann. Glaciol. 35, 538-544, 2002.

Keegan, K. M., Albert, M. R., McConnell, J. R., and Baker, I.: Climate change and forest fires synergistically drive widespread melt events of the Greenland Ice Sheet, P. Natl. Acad. Sci. USA, 111, 7964-7967, 2014.

Luciano, G. L. and Albert, M. R.: Bidirectional permeability measurements of polar firn, Ann. Glaciol., 35, 63-66, 2002.

NEEM Community Members: Eemian interglacial reconstructed from a Greenland folded ice core, Nature, 493, 489-494, 2013.

Neftel, A., Oeschger, H., Schwander, J., and Stauffer, B.: Carbon dioxide concentration in bubbles of natural cold ice, J. Phys. Chem., 87, 4116-4120, 1983.
Nghiem, S. V., Hall, D. K., Mote, T. L., Tedesco, M., Albert, M. R., Keegan, K., Shuman, C. A., DiGirolamo, N. E., and Neumann, G.: The extreme melt across the Greenland ice sheet in 2012, Geophys. Res. Lett., 39, L20502, doi:10.1029/2012GL053611, 2012.

Schwander, J. and Stauffer, B.: Age difference between polar ice and the air trapped in its bubbles, Nature, 311, 45-47, 1984.

Schwander, J., Barnola, J.-M., Andrie, C., Leuenberger, M., Ludin, A., Raynaud, D., and Stauffer, B.: The age of the air in the firn and the ice at Summit, Greenland, J. Geophys. Res., 98, 28312838, 1993.

Sigl, M., McConnell, J. R., Layman, L., Maselli, O., McGwire, K., Pasteris, D., Dahl-Jensen, D., Steffensen, J. P., Vinther, B., Edwards, R., Mulvaney, R., and Kipfstuhl, S.: A new bipolar ice core record of volcanism from WAIS Divide and NEEM and implications for climate forcing of the last 2000 years, J. Geophs. Res. Atmos., 118, 1151-1169, 2013.

Trudinger, C. M., Enting, I. G., Etheridge, D. M., Francey, R. J., Levchenko, V. A., Steele, L. P., Raynaud, D., and Arnaud, L.: Modeling air movement and bubble trapping in firn, J. Geophys. Res., 102, 6747-6763, 1997. 